\title{
Optimal Laparoscopic Management and Oncological Outcomes of Gastrointestinal Stromal Tumors in Duodenum: Pancreaticoduodenectomy or Pancreas-Sparing Duodenectomy?
}

This article was published in the following Dove Press journal: Cancer Management and Research

\author{
Chao $\mathrm{Lu}^{\mathrm{I}-3}$ \\ Weiwei Jin ${ }^{1,2}$ \\ Yiping Mou ${ }^{1,2}$ \\ Hongliang Shao ${ }^{4}$ \\ Xiaosan $\mathrm{Wu}^{4}$ \\ Shaodong $\mathrm{Li}^{5}$ \\ Biwu $\mathrm{Xu}^{4}$ \\ Yuanyu Wang (iD) ${ }^{1,2}$ \\ Qicong Zhu ${ }^{1,2}$ \\ Tao Xia ${ }^{1,2}$ \\ Yucheng Zhou ${ }^{1-3}$ \\ 'Department of Gastrointestinal and \\ Pancreatic Surgery, Zhejiang Provincial \\ People's Hospital, Hangzhou, Zhejiang \\ Province, People's Republic of China; \\ ${ }^{2}$ Key Laboratory of Gastroenterology of \\ Zhejiang Province, Hangzhou, Zhejiang \\ Province, People's Republic of China; \\ ${ }^{3}$ School of Medicine, Soochow University, \\ Suzhou, Jiangsu Province, People's \\ Republic of China; ${ }^{4}$ School of Medicine, \\ Bengbu Medical College, Bengbu, Anhui \\ Province, People's Republic of China; \\ ${ }^{5}$ School of Medicine, Zhejiang Chinese \\ Medical University, Hangzhou, Zhejiang \\ Province, People's Republic of China
}

Correspondence: Yucheng Zhou; Yiping Mou

Department of Gastrointestinal and Pancreatic Surgery, Zhejiang Provincial People's Hospital, Hangzhou, Zhejiang Province, People's Republic of China Email drzhouyc@163.com; yipingmou@।26.com
Background: Gastrointestinal stromal tumors (GIST) of the duodenum are rarely reported and optimal minimally invasive management has not been well proposed. Pancreaticoduodenectomy and different types of pancreas-sparing duodenectomy can be chosen; however, which to choose and its corresponding clinical outcomes and oncological concerns remain controversial.

Patients and Methods: Patients diagnosed with GIST of duodenum underwent laparoscopic pancreaticoduodenectomy (L-PD) or pancreas-sparing duodenectomy (L-PSD) in Zhejiang Provincial People's Hospital were enrolled. All prospectively maintained data were analyzed retrospectively. Patients were grouped into the L-PD group or the L-PSD group, and the clinical outcomes and oncological outcomes were analyzed.

Results: Between June 2013 and March 2019, a total of 22 patients (11 males/11 females) underwent surgical management, including 13 L-PDs and 9 L-PSDs. The average age was 58.2 \pm 9.5 year-old (median 60.5 year-old). The most common presentations were GI bleeding (54.5\%) and abdominal discomfort (27.2\%), and the dominant lesion located in the second portion of duodenum (59.1\%). Compared with L-PD group, L-PSD group showed much shorter operation time ( $364.2 \pm 58.7 \mathrm{~min}$ vs. $230.0 \pm 12.3 \mathrm{~min}, \mathrm{P}<0.001)$, less blood loss $(176.9 \pm 85.7 \mathrm{~mL}$ vs. $61.1 \pm 18.2 \mathrm{~min}, \mathrm{P}<0.001)$, faster recovery to off-bed ( $2.6 \pm 1.3 \mathrm{~d}$ vs. $1.1 \pm 0.3 \mathrm{~d}, \mathrm{P}=0.003)$, anus flatus ( $4.5 \pm 1.0 \mathrm{~d}$ vs. $2.4 \pm 0.5 \mathrm{~d}, \mathrm{P}<0.001)$ and liquid intake $(4.9 \pm 1.3 \mathrm{~d}$ vs. $2.3 \pm 0.5 \mathrm{~d}, \mathrm{P}<0.001)$. Lymph node retrieval was much less in L-PSD, but no lymph node metastasis was observed in any patients. L-PSD had much Lower morbidity of both minor (Grade I/II) and major (III/IV/V) complications than that of L-PD $(11.1 \%$ vs. $61.6 \%, \mathrm{P}=0.02)$, resulting in shorter hospital stays (10.9 \pm 3.8 d vs. $20.6 \pm 11.1 \mathrm{~d}, \mathrm{P}=0.021)$ and less total cost $(76,972.4 \pm 11,614.8$ yuan vs $125,628.7$ $\pm 46,356.8$ yuan, $\mathrm{P}=0.006$ ). The median follow-up was 42 months (range from 12 to 82 months) without loss. Only 1 L-PD patient suffered hepatic metastasis 36 months after surgery, and given sunitinib to stabilize the disease, none of the rest observed recurrence or metastasis.

Conclusion: For GIST located opposite the major papilla, L-PSD showed comparable safety and oncological benefits when compared to L-PD, with shorter operation time, less blood loss and much faster recovery time, resulting in much less total cost. L-PSD should be applied in selected patients with experienced hands.

Keywords: GIST, duodenum, pancreaticoduodenectomy, pancreas-sparing duodenectomy

\section{Introduction}

Gastrointestinal stromal tumors (GISTs) were reported to be the most common mesenchymal tumors in gastrointestinal tract derived from the Cajal cells. ${ }^{1}$ GISTs 
can occur throughout the entire digestive tract; however, the prevailing locations are in the stomach (50-60\%) and small intestine (30-35\%), duodenal GISTs account for only $3-5 \% .^{2}$ Rare as duodenal GISTs are, the optimal surgical treatment and prognosis remain controversial.

For duodenal GISTs, complete surgical resection with negative margins is the criteria for curative management. Pancreaticoduodenectomy (PD) is commonly performed in terms of the potential of uncertain malignancy and proximity to adjacent pancreatico-biliary organs. However, in most cases PD was considered too aggressive even for oncological reasons with "innocent" resection of pancreas and bile duct, ${ }^{3}$ moreover, the reconstructions on un-dilated ducts were technically demanding and exerted great risks on postoperative complications. $^{2-5}$ Pancreas-sparing duodenectomy (PSD) with a negative margin was reported to be technically feasible and presumed to have more functional preservation, ${ }^{3-6}$ while providing comparable recurrent rate, ${ }^{5,6}$ and even better long-term prognosis. $^{2}$ Recently, more and more attempts were stressed on the indication and various surgical procedures, ${ }^{2,5,7}$ however, no routine methods were established because of the limited cases.

Minimal invasive surgery was recommended for gastric GISTs in various guidelines. ${ }^{8}$ However, for duodenal GISTs, the optimal minimally invasive surgical (MIS) management has not been proposed or described well. Proper indications and MIS method for different types of pancreas-sparing duodenectomy remained undefined. Moreover, its safety and oncological outcomes were controversial due to few published reports. ${ }^{3,9-11}$ In this study, we retrospectively concluded and analyzed the clinical outcomes of duodenal GIST that underwent different MIS treatments, including morbidity, economic cost and long-term survival data, then recommend the optimal MIS choice for duodenal GIST.

\section{Patients and Methods}

\section{Patients and Methods}

Patients who had been diagnosed with duodenal GIST and underwent minimally invasive procedures between June 2013 and March 2019 in Zhejiang Provincial People's Hospital were enrolled. All lesions were evaluated by CT scan and diagnostic endoscopy, intended for excluding the possibilities of endoscopic resections and confirming the location of the tumor and Vater's papilla as well. Surgical managements included minimally invasive procedures, and varied from pancreaticoduodenectomy to different types of pancreas-sparing duodenectomy based on tumor size and location. This study was approved by the Institutional Review Board and Ethics Committees of Zhejiang Provincial People's Hospital. All patients were informed with the written consents in accordance with the Declaration of Helsinki.

All the clinical data were retrospectively reviewed based on prospectively maintained database, including perioperative data, pathological parameters, adjuvant therapy, morbidity, mortality and long-term oncological outcomes. Pathological diagnosis was confirmed by 2 specialized pathologist and risk stratifications were classified based on NIH consensus. $^{12}$ Pancreatic fistula and postoperative hemorrhage were defined and classified according to the International Study Group of Pancreatic Fistula (ISGPF) criteria. ${ }^{13,14}$ Furthermore, complications were all classified using the Clavien-Dindo classification. ${ }^{15}$ All the clinical outcomes of duodenal GIST that underwent PD and PSD were compared, including morbidity, economic cost and long-term survival.

\section{Indication and Surgical Techniques}

All patients underwent minimally invasive procedure with the intent to completely remove tumors without rupture. The extent of procedure and various types of operation were determined based on the tumor size and proximity to the Vater's papilla (Figure 1). For duodenal GISTs with diameter greater than $5 \mathrm{~cm}$ or lesions located on the same side of the major duodenal papilla, laparoscopic pancreaticoduodenectomy (L-PD) was indicated and performed. However, for supraampulla and infra ampulla duodenal GISTs that were less than $5 \mathrm{~cm}$, and the lesions that were located opposite to the major papilla, laparoscopic pancreas-sparing duodenectomy (L-PSD) was suggested and performed.

\section{Laparoscopic Pancreaticoduodenectomy (L-PD)}

The L-PD procedure has been described in a previously published study. ${ }^{15}$ All L-PDs were performed as standard PD without pylorus preservation. We routinely used the modified approach based on the "Five Trocars" method to perform L-PD (Figure 2). Make sure to dissect the specimen gently and never grab the tumor directly to prevent tumor rupturing and spreading. After the specimens were removed from the enlarged umbilical port, a frozen section was sent to confirm the duodenal GISTs and negative margins. Because of the un-dilated pancreatic and bile ducts, the reconstruction 


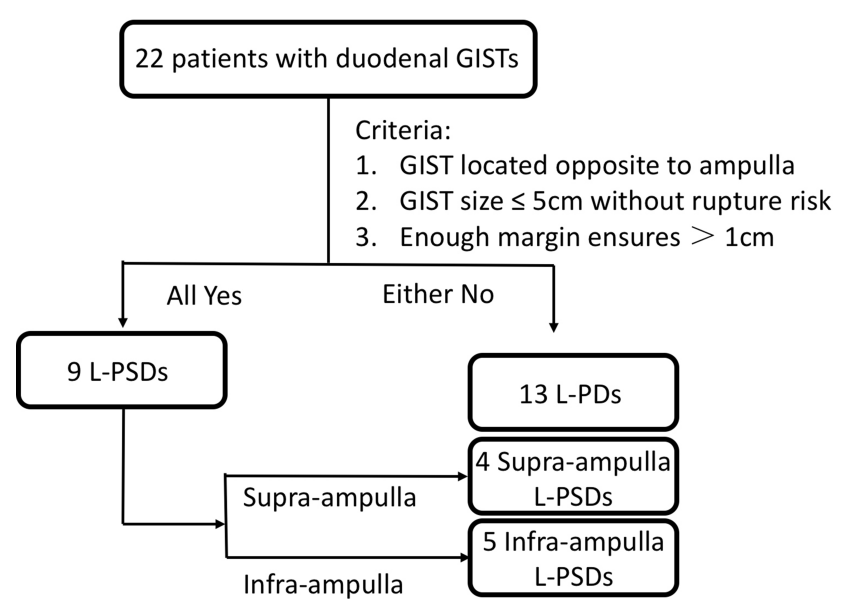

Figure I Flow diagram and indication for laparoscopic pancreaticoduodenectomy (L-PD) or laparoscopic pancreas-sparing duodenectomy (L-PSD) for duodenal GISTs.

was performed with duct-to-mucosa pancreatojejunostomy and interrupted sutures hepaticojejunostomy. ${ }^{16}$

\section{Laparoscopic Pancreas-Sparing Duodenectomy (L-PSD)}

For small duodenal lesions located opposite the major papilla, different types of L-PSD were performed based on the relative location of the Vater's papilla (Figures 3 and 4). These patients underwent preoperative endoscopy (Figure 3A), intended to evaluate and locate the proximal/ distal margins of tumors and the Vater's papilla. Dye or clips were also used (Figure 3B).

For supra-ampulla lesions (Figure 3), the gastro-colic ligament was divided first and then the Kocher maneuver was made to have better exposure of the pancreatic head and the duodenal. After the right gastro-epipoloic vessels were dissected, we used ultrasonic shears to gradually separate the duodenum from the pancreatic head, all the vessels that supply to the targeted duodenum rather than pancreas were carefully dissected and coagulated from cephalad to caudad (Figure 3C). Then the dissection plane was extended stepwise to the pre-set margin marked by dye or clips. After mobilization, the proximal margin was transected by linear stapler. However, when dissecting the distal margin one should not use a stapler to keep the ampulla intact. Usually, we incised directly along the preset margin (Figure 3D) and perform Intraoperative cholangiogram (IOC) to locate the ampulla with definite preservation. We keep the catheter along the common bile duct all the way to the outlet of ampulla (Figure 3E and F), and with the guidance of catheter the opening was closed by hand-sewn suture without injuring the ampulla (Figure 3G). At last, an ante-colic loop gastrojejunostomy was completed approximately $20 \mathrm{~cm}$ from the Treiz ligament.

As for infra-ampulla lesions (Figure 4), the duodenum was also exposed by dividing the gastro-colic ligament and Kocherization. Moreover, complete separation from retroperitoneum and mesocolon was completed to detach the descending and horizontal parts of the duodenum. Next, proximal jejunum for distal margin was mobilized from the Treitz ligament and transected with a linear stapler, then placed it to the right of the SMA through the retromesenteric root. Similarly, all the responsible vessels along the inferior border of the uncinate process were carefully dissected and coagulated from left to right till the preset proximal margin around ampulla. After clamping the preset margin, routine IOC was performed to make

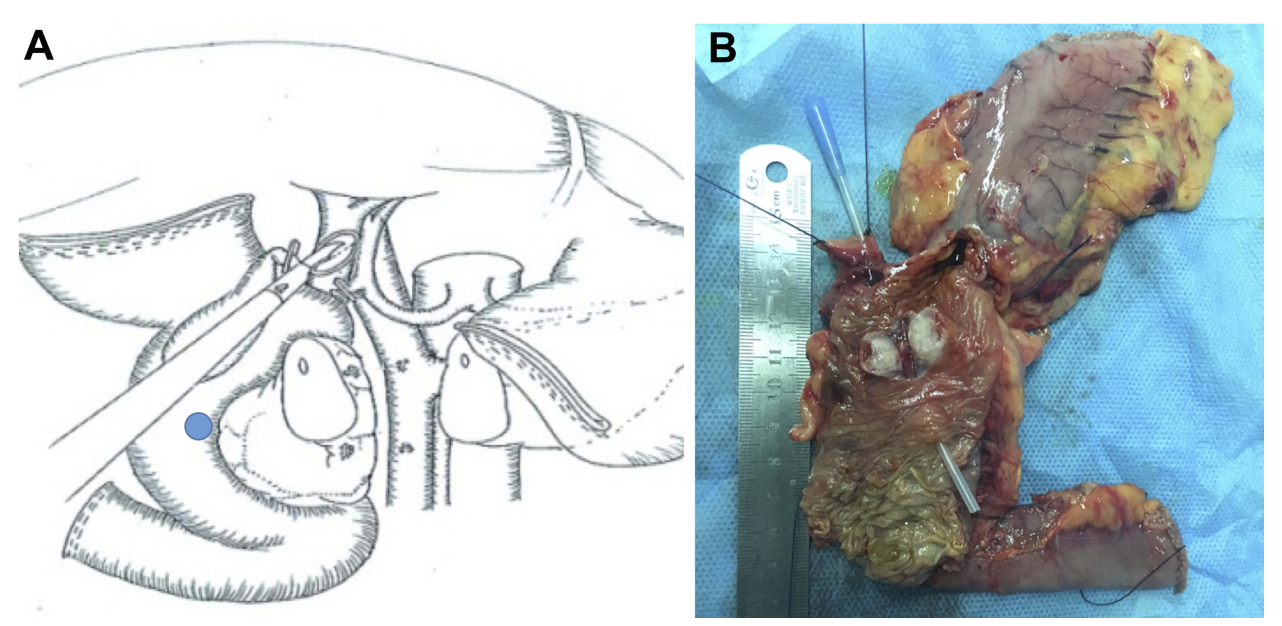

Figure 2 For lesions adjacent to papilla, laparoscopic pancreaticoduodenectomy was indicated and performed (A). The blue spot represented the duodenal GISTs. (B) Shows the resected specimen with ulcerative lesions in the same side of papilla. 

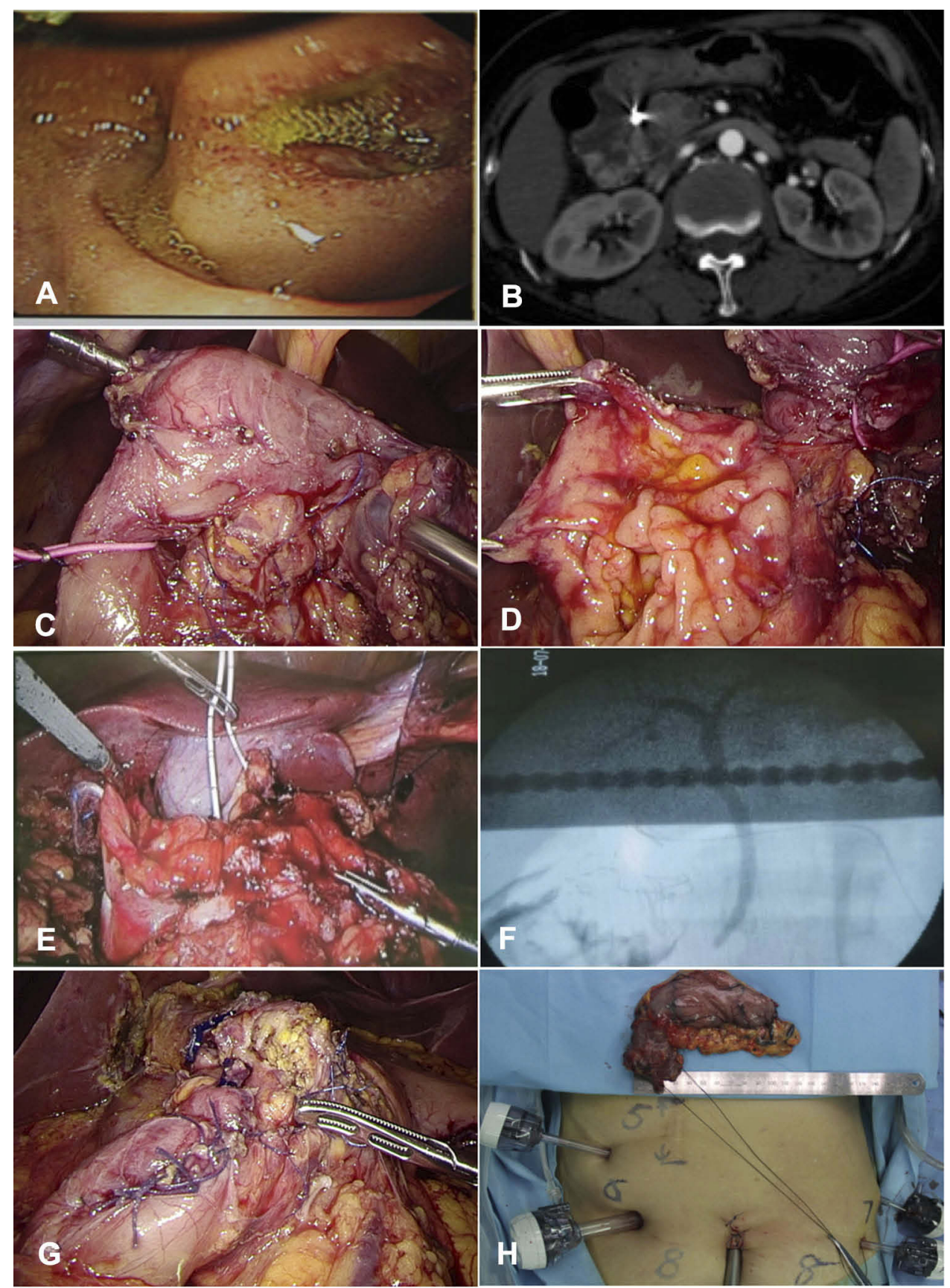

Figure 3 Laparoscopic pancreas-sparing duodenectomy (L-PSD) for supra-ampulla lesions. Diagnostic endoscopy was used to exclude possibility of endoscopic resections (A) and marking the tumor location to papilla (B). Supra-ampulla duodenum was gradually separated from the pancreas (C), and the distal margin was transected without stapler for preserving the ampulla intact (D). With the guidance of catheter along the common bile duct (E), intraoperative cholangiogram (IOC, 3F) was also performed to locate the papilla. With the help of catheter, the opening was closed without injury the papilla $(\mathbf{G})$. (H) Shows the trocar distribution and the specimen.

sure the ampulla was intact as described previously. After that, the proximal margin was transected by linear stapler (Figure 4B), and a side-to-side duodenojejunostomy was done in a retro-colic manner.

Preserving the function of the major duodenal papilla is critical and is the ultimate goal for both supra- and infraampulla L-PSD. So cholecystectomy is needed for all
L-PSD to perform IOC, and ensure the preservation of the papilla.

\section{Adjuvant Imatinib and Follow-Up}

For patients classified as moderate-risk and high-risk grade according to NIH criteria, adjuvant Imatinib with $400 \mathrm{mg}$ per day was indicated and recommended for 3 year and 5 

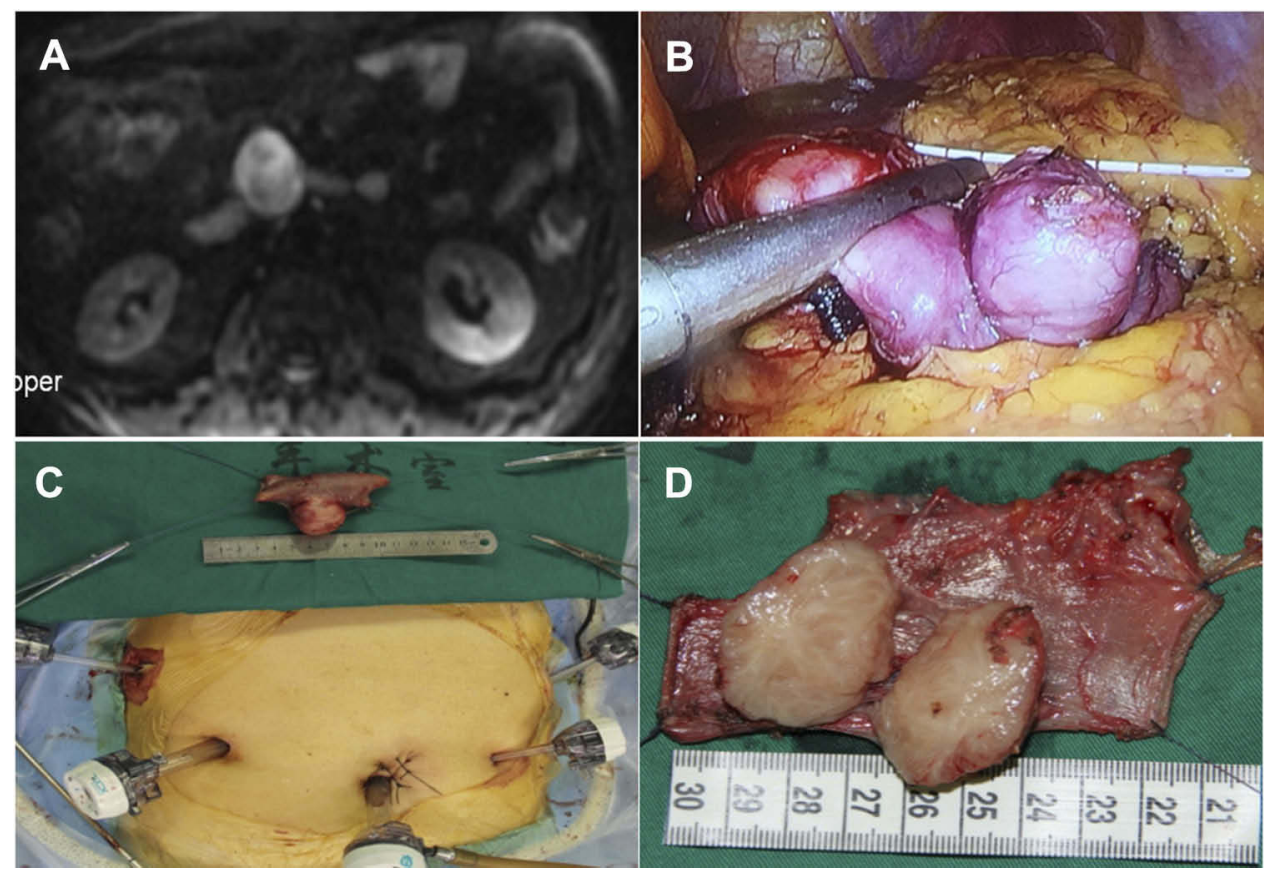

Figure 4 Laparoscopic pancreas-sparing duodenectomy (L-PSD) for infra-ampulla lesions. Lesions located in the 3rd part of duodenum (A). After clamping the pre-set margin (B), before transection by stapler, IOC was performed to confirm the papilla intact. (C and D) Show the trocar distribution and the resected specimen, respectively.

years, respectively. Regular follow-up for every 3 months was obtained by medical records and telephone. Computed tomography and endoscopy were carried out every 6 months and 12 months, respectively. Recurrence was evaluated by multi-disciplinary team (MDT) discussion.

\section{Statistical Analysis}

Continuous data were expressed as means \pm standard deviations, and the categorized data were summarized as frequencies and percentages. The student $t$-test and Fisher exact $\chi^{2}$ test were used to compare the differences between the PD group and the PSD group. PFS and OS curves were determined using the KaplanMeier method and survival differences were compared by the $\log$ rank test. $P$ value $<0.05$ was considered statistically significant. All of the data were analyzed by R 3.5.1 (R Foundation for Statistical Computing, Vienna, Austria).

\section{Results}

\section{Demographic and Clinico-Pathological Characteristics}

Twenty-two patients diagnosed with duodenal GIST underwent laparoscopic surgery and were enrolled, including 13 L-PDs and 9 L-PSDs. All patients' demographic characteristics are listed in Table 1.
The average age was 58.2 \pm 9.5 year-old (Median 60.5 year-old). The most common presentations were GI bleeding (54.5\%) and abdominal discomfort (27.2\%), and the dominant lesion was located in the second portion of duodenum (59.1\%). Most of the tumors $(72.7 \%)$ were smaller than $5 \mathrm{~cm}$. According to the grading system by $\mathrm{NIH}$, pathology confirmed $4(18.2 \%)$ as very low risk, 10 $(45.5 \%)$ as low risk, $0(0 \%)$ as moderate risk and $8(36.3 \%)$ as high risk, respectively. As to the mitotic count, $<5 /$ 50HPF accounts for $91 \%$. No lymph nodes metastasis was observed. $7(31.8 \%)$ of patients were classified as high-grade risk and received adjuvant Imatinib.

\section{Operative Outcomes and Complications}

Based on tumor size and proximity to the Vater's papilla, L-PD (Table 2) and different types of L-PSD were performed (Table 3). Thirteen duodenal GISTs underwent LPDs. And L-PSD were all performed with duodenal GISTs located opposite the major papilla, including 4 supra-ampulla L-PSDs and 5 infra-ampulla L-PSDs (Tables 1 and 3).

Compared with the L-PD group, the L-PSD group showed much shorter operation times $(364.2 \pm 58.7 \mathrm{~min}$ vs. $230.0 \pm 12.3 \mathrm{~min}, \mathrm{P}<0.001)$, less blood loss $(176.9 \pm 85.7 \mathrm{~mL}$ vs. $61.1 \pm 18.2 \mathrm{~min}, \mathrm{P}<0.001)$, faster recovery to off-bed (2.6 $\pm 1.3 \mathrm{~d}$ vs. $1.1 \pm 0.3 \mathrm{~d}, \mathrm{P}=0.003)$, anus flatus $(4.5 \pm 1.0 \mathrm{~d}$ 
Table I Demographic and Clinico-Pathological Characteristics for 22 Duodenal GISTs

\begin{tabular}{|c|c|}
\hline All Patients $(n=22)$ & n (\%) \\
\hline Sex & 22 \\
\hline Male & II (50\%) \\
\hline Female & II (50\%) \\
\hline Age (Median) & $58.2 \pm 9.5(60.5)$ \\
\hline \multicolumn{2}{|l|}{ Symptoms } \\
\hline Gastrointestinal bleeding & $12(54.5 \%)$ \\
\hline Abdominal pain & $6(27.2 \%)$ \\
\hline Asymptomatic & $4(18.2 \%)$ \\
\hline \multicolumn{2}{|l|}{ Tumor Site } \\
\hline DI (Ist portion of duodenum) & $2(9.1 \%)$ \\
\hline D2 (2nd portion of duodenum) & $13(59.1 \%)$ \\
\hline D3 (3rd portion of duodenum) & $6(27.3 \%)$ \\
\hline D4 (4th portion of duodenum) & I (4.5\%) \\
\hline \multicolumn{2}{|l|}{ Tumor Size } \\
\hline$\varphi_{\max } \leq 2 \mathrm{~cm}$ & $4(18.2 \%)$ \\
\hline $2<\varphi_{\max } \leq 5 \mathrm{~cm}$ & $12(54.5 \%)$ \\
\hline $5 \mathrm{~cm}<\varphi_{\max } \leq 10 \mathrm{~cm}$ & $4(18.2 \%)$ \\
\hline$\varphi_{\max }>10 \mathrm{~cm}$ & $2(9.1 \%)$ \\
\hline \multicolumn{2}{|l|}{ Surgical management } \\
\hline Laparoscopic pancreaticoduodenectomy (L-PD) & $13(59.1 \%)$ \\
\hline $\begin{array}{l}\text { Laparoscopic pancreas-sparing duodenectomy } \\
\text { (L-PSD) }\end{array}$ & 9 (40.9\%) \\
\hline Supra-ampulla L-PSD & $4(18.2 \%)$ \\
\hline Infra-ampulla L-PSD & $5(22.7 \%)$ \\
\hline \multicolumn{2}{|l|}{ Risk stratification of NIH criteria } \\
\hline Very low risk & $4(18.2 \%)$ \\
\hline Low risk & $10(45.4 \%)$ \\
\hline Intermediate risk & $0(0 \%)$ \\
\hline High risk & $8(36.4 \%)$ \\
\hline \multicolumn{2}{|l|}{ Mitotic count } \\
\hline$\leq 5 / 50 \mathrm{HPF}$ & 20 (9|\%) \\
\hline$>5 / 50 \mathrm{HPF}$ & $2(9 \%)$ \\
\hline Adjuvant Imatinib & 7 (31.8\%) \\
\hline
\end{tabular}

vs. $2.4 \pm 0.5 \mathrm{~d}, \mathrm{P}<0.001)$ and liquid intake $(4.9 \pm 1.3 \mathrm{~d}$ vs. 2.3 $\pm 0.5 \mathrm{~d}, \mathrm{P}<0.001)$. Lymph node retrieval was much less in L-PSD, but no lymph node metastasis was observed in any patients. Moreover, according to the Clavien-Dindo classification, L-PSD had a much lower morbidity of both minor (Grade I/II) and major (III/IV/V) complications than that of L-PD ( $11.1 \%$ vs. $61.6 \%, \mathrm{P}=0.02)$, resulting in shorter length of hospital stay $(10.9 \pm 3.8 \mathrm{~d}$ vs. $20.6 \pm 11.1 \mathrm{~d}$, $\mathrm{P}=0.021)$ and less total cost $(76,972.4 \pm 11,614$.8yuan vs $125,628.7 \pm 46,356.8$ yuan, $\mathrm{P}=0.006$ ). However, reoperation rate and mortality failed to reach significant difference. Of note, all the 3 reoperations occurred in L-PD group, 2 of which complicated with pancreaticojejunostomy leakage presented as bleeding in postoperative day (POD) 7 and abdominal infection in POD5, respectively, and underwent reoperation with external drainage of the end loop together with main pancreatic duct; moreover, nutritional jejunostomy was suggested in the efferent loop. Finally, these 2 patients discharged in POD20 and POD23 without other morbidity. However, the rest one suffered bleeding due to pancreatic leakage in POD6 with reoperation; however, multi-organ dysfunction developed and resulted in death in POD15. Regarding late complication, L-PD had one stricture of hepaticojejunostomy 6 months after surgery (Table 4).

\section{Follow-Up and Oncological Outcomes}

Regular follow-up was carried out and the median followup was 42 months (Ranging from 12 to 82months) without loss. Except for the perioperative mortality, the rest 7 patients with high-grade risk stratification, adjuvant Imatinib was recommended that lasted 60 months. During the follow-up, only 1 L-PD patient suffered hepatic metastasis 36 months after surgery, and sunitinib was given to maintain stabilize the disease, none of the rest observed recurrence or metastasis. No significant differences of overall survival (OS) and disease-free survival (DFS) were observed between the L-PD and the L-PSD group (Figure 5). Except for one mortality because of a major complication, the other 21 patients survived.

\section{Discussion}

Since duodenal GISTs are rare, the optimal surgical managements and oncological outcomes remain unclear. Generally, pancreaticoduodenectomy (PD) is indicated for duodenal GISTs for its uncertain malignancy and proximity to bilio-pancreatic ampulla. Moreover, it is technically difficult in a duodenectomy to dissect the duodenum from the pancreatic head because of their intimate relation both in anatomy and function. However, as the surgical skills and energy equipment developed, difficulties turned to feasibility ${ }^{3,9,11}$ and the higher complication rate after PD outweighs its benefits. ${ }^{2}$ Studies seldom compared the postoperative complications of PSD with PD directly or oncological outcomes for duodenal GISTs, especially for minimal invasive management.

In this study, duodenal GISTs that underwent L-PD suffered alarming morbidity and mortality, $61.6 \%$ of 
Table 2 Clinico-Pathological Detail and Follow-Up of All L-PDs

\begin{tabular}{|c|c|c|c|c|c|c|c|c|c|}
\hline \multirow[t]{2}{*}{ Case } & \multirow{2}{*}{$\begin{array}{l}\text { Sexl } \\
\text { Age }\end{array}$} & \multirow[t]{2}{*}{ Symptom } & \multirow{2}{*}{$\begin{array}{l}\text { Size } \\
(\mathrm{cm})\end{array}$} & \multicolumn{2}{|l|}{ Location } & \multirow{2}{*}{$\begin{array}{l}\text { Mitotic } \\
\text { Count }\end{array}$} & \multirow[t]{2}{*}{ Risk } & \multirow{2}{*}{$\begin{array}{l}\text { Adjuvant } \\
\text { Imatinib }\end{array}$} & \multirow[t]{2}{*}{ OS } \\
\hline & & & & Opposite & $\begin{array}{l}\text { Sup.l } \\
\text { Inf. }\end{array}$ & & & & \\
\hline I & $M / 64$ & Asymptomatic & 2.5 & No & Adjacent & 2/50HPF & Low & No & 81.9 months \\
\hline 2 & $M / 58$ & GI Bleeding & 3 & No & Inferior & I/50HPF & Low & No & 76.2 months \\
\hline 3 & $M / 42$ & GI Bleeding & 3 & No & Adjacent & $5 / 50 \mathrm{HPF}$ & Low & No & 69.7 months \\
\hline 4 & $M / 70$ & GI Bleeding & 3 & No & Superior & I/50HPF & Low & No & 54.5 months \\
\hline 5 & $\mathrm{~F} / 59$ & Pain & 8 & Yes & I & $2 / 50 \mathrm{HPF}$ & High & Yes & 54.5 months \\
\hline 6 & $M / 56$ & GI Bleeding & 5.5 & No & I & $2 / 50 \mathrm{HPF}$ & High & Yes & 53.9 months \\
\hline 7 & $\mathrm{~F} / 63$ & GI Bleeding & 4.2 & No & Adjacent & $7 / 50 \mathrm{HPF}$ & High & Yes & 45.7 months \\
\hline 8 & $F / 36$ & GI Bleeding & 12 & No & I & 4/50HPF & High & Yes & 41.8 months* \\
\hline 9 & $M / 68$ & Asymptomatic & 16 & No & I & $2 / 50 \mathrm{HPF}$ & High & No & Mortality \\
\hline 10 & $\mathrm{~F} / 60$ & Gl Bleeding & 6 & No & Adjacent & 4/50HPF & High & Yes & 22.6 months \\
\hline 11 & $\mathrm{~F} / 67$ & Asymptomatic & 1.5 & No & Adjacent & I/50HPF & Very Low & No & 12.0 months \\
\hline 12 & $\mathrm{~F} / 6 \mathrm{I}$ & GI Bleeding & 2 & No & Adjacent & I/50HPF & Very Low & No & 17.5 months \\
\hline 13 & $M / 52$ & Pain & 7 & No & Adjacent & $2 / 50 \mathrm{HPF}$ & High & Yes & 16.5 months \\
\hline
\end{tabular}

Note: *Hepatic metastasis ocurred 36 months after surgery, followed by sunitinib.

Table 3 Clinico-Pathological Detail and Follow-Up of All L-PSDs

\begin{tabular}{|c|c|c|c|c|c|c|c|c|c|}
\hline \multirow[t]{2}{*}{ Case } & \multirow[t]{2}{*}{$\begin{array}{l}\text { Sexl } \\
\text { Age }\end{array}$} & \multirow[t]{2}{*}{ Symptom } & \multirow[t]{2}{*}{$\begin{array}{l}\text { Size } \\
(\mathrm{cm})\end{array}$} & \multicolumn{2}{|c|}{$\begin{array}{l}\text { Location to } \\
\text { Ampulla }\end{array}$} & \multirow[t]{2}{*}{$\begin{array}{l}\text { Mitotic } \\
\text { Count }\end{array}$} & \multirow[t]{2}{*}{ Risk } & \multirow[t]{2}{*}{$\begin{array}{l}\text { Adjuvant } \\
\text { Imatinib }\end{array}$} & \multirow[t]{2}{*}{ OS } \\
\hline & & & & Opposite & $\begin{array}{l}\text { Sup.I } \\
\text { Inf. }\end{array}$ & & & & \\
\hline 1 & $\mathrm{~F} / 63$ & Gl Bleeding & 1.6 & Yes & Superior & 5/50HPF & Very low & No & 53.I months \\
\hline 2 & $M / 59$ & GI Bleeding & 3.0 & Yes & Inferior & 8/50HPF & High & Yes & 50.8 months \\
\hline 3 & $\mathrm{~F} / 7 \mathrm{I}$ & Pain & 2.0 & Yes & Superior & 2/50HPF & Very Low & No & 44.6 months \\
\hline 4 & $M / 46$ & Pain & 3.3 & Yes & Superior & I/50HPF & Low & No & 30.3 months \\
\hline 5 & $\mathrm{~F} / 50$ & Pain & 4.0 & Yes & Inferior & I/50HPF & Low & No & 24.2 months \\
\hline 6 & $M / 66$ & Asymptomatic & 4.0 & Yes & Inferior & I/50HPF & Low & No & 25.3 months \\
\hline 7 & $\mathrm{~F} / 65$ & Gl Bleeding & 2.5 & Yes & Superior & 2/50HPF & Low & No & 14.9 months \\
\hline 8 & $\mathrm{~F} / 44$ & Pain & 4.6 & Yes & Inferior & 4/50HPF & Low & No & 14.5 months \\
\hline 9 & $M / 6 I$ & Gl Bleeding & 3 & Yes & Inferior & 4/50HPF & Low & No & 14.0 months \\
\hline
\end{tabular}

patients had postoperative complications and half of them (30.8\%) experienced major complications (Clavien-Dindo Grade III-V), much higher than that of routine L-PDs. Only $32.2 \%$ of patients in our previously 320 consecutive L-PDs developed morbidity with $10.9 \%$ developing major complications. ${ }^{16}$ To compare from national and international perspectives, Wang et al reported L-PD with $49.66 \%$ morbidity out of 1029 multi-center patients in China and $21.2 \%$ major complications, ${ }^{17}$ Adam from the US concluded that the complication rate was $47 \%$ out of 865 minimally invasive PD patients. ${ }^{18}$ Unlike with other periampullary lesions, duodenal GISTs seldom obstruct the bile ducts and pancreatic ducts, the un-dilated ducts and soft texture of pancreas exert great difficulty for reconstruction and resulted in an alarmingly higher morbidity than that of routine L-PDs, in this study $46 \%$ of patients ended up with POPF, including 23.1\% Grade $\mathrm{C}$ POPF needing reoperation. It was also true with bile leakage at $15.4 \%$, much higher than that of our previous study with $17.5 \%$ POPF and $3.8 \%$ bile leakage. ${ }^{16}$ Stricken by this, L-PSD was explored in selected patients when technically possible, avoiding troublesome biliary-enteric and pancreatic-enteric anastomoses.

Varied nomination of different types of duodenectomy were adopted and reported based on tumor location and vicinity to the ampulla, including limited or wedge resection, ${ }^{2,4-7,10,20}$ segmental duodenectomy, ${ }^{9,10}$ partial sleeve duodenectomy $y^{3,9}$ and pancreas-sparing duodenectomy. ${ }^{11,19}$ As 
Table 4 Peri-Operative Outcomes and Postoperative Complications

\begin{tabular}{|c|c|c|c|}
\hline \multirow[t]{2}{*}{ Operative Outcomes and Complications } & \multicolumn{2}{|l|}{ n (\%) } & \multirow[t]{2}{*}{$P$ value } \\
\hline & L-PD Group & L-PSD Group & \\
\hline $\begin{array}{l}\text { Operative time (min) } \\
\text { Blood loss }(\mathrm{mL}) \\
\text { Blood transfusion }(\mathrm{n}) \\
\text { Intensive care unit stay }(\mathrm{n}) \\
\text { Retrieved lymph nodes } \\
\text { Metastatic lymph nodes }\end{array}$ & $\begin{array}{l}364.2 \pm 58.7 \\
176.9 \pm 85.7 \\
3(23.1 \%) \\
2(15.4 \%) \\
11.6 \pm 7.2 \\
0\end{array}$ & $\begin{array}{l}230.0 \pm 12.3 \\
61.1 \pm 18.2 \\
0(0 \%) \\
0(0 \%) \\
1.3 \pm 2.0 \\
0\end{array}$ & $\begin{array}{l}<0.001 \\
<0.001 \\
0.36 \\
0.63 \\
<0.001 \\
1.00\end{array}$ \\
\hline $\begin{array}{l}\text { Postoperative complications } \\
\text { Minor complications (Grade I/I*) } \\
\text { Biochemical POPF (Grade I) } \\
\text { Grade A Bile leakage with draining (Grade II) } \\
\text { Grade A Hemorrhage (Grade II) } \\
\text { Delayed gastric emptying (Grade II) } \\
\text { Major complications (Grade III/IV/V*) } \\
\text { Grade B POPF with drainage (Grade IIla) } \\
\text { Grade B Bile leakage with drainage (Grade IIIa) } \\
\text { Grade C POPF with reoperation (Grade IIIb) } \\
\text { Grade C POPF leading to death (Grade V) }\end{array}$ & $\begin{array}{l}8(61.6 \%) \\
4(30.8 \%) \\
2(15.4 \%) \\
\text { I (7.7\%) } \\
\text { I (7.7\%) } \\
0(0 \%) \\
4(30.8 \%) \\
\text { I (7.7\%) } \\
\text { I (7.7\%) } \\
2(15.4 \%) \\
\text { I (7.7\%) }\end{array}$ & $\begin{array}{l}\text { I (II.I\%) } \\
\text { I (II.I\%) } \\
0 \\
0 \\
\text { I (II.I\%) } \\
0(0 \%) \\
0 \\
0 \\
0 \\
0\end{array}$ & 0.02 \\
\hline $\begin{array}{l}\text { Late hepaticojejunostomy stricture } \\
\text { Reoperation } \\
\text { Mortality } \\
\text { Length of hospital stay (day, Median) }\end{array}$ & $\begin{array}{l}\text { I }(7.7 \%) \\
3(23.1 \%) \\
\text { I (7.7\%) } \\
20.6 \pm I 1 . \mid(16)\end{array}$ & $\begin{array}{l}0(0 \%) \\
0(0 \%) \\
0(0 \%) \\
10.9 \pm 3.8(10)\end{array}$ & $\begin{array}{l}0.84 \\
0.36 \\
0.85 \\
0.021\end{array}$ \\
\hline
\end{tabular}

Note: *Refer to Clavien-Dindo Classification of surgical complications.

all the procedures above aim to resect the duodenal lesions while preserving the pancreas and ampulla, pancreas-sparing duodenectomy (PSD) was believed to be more generalized and PSD was adopted. L-PSD was only indicated for supraampulla and infra ampulla duodenal GISTs $<5 \mathrm{~cm}$, and lesions located opposite the major papilla. For both supra and infra L-PSD, guaranteed negative margin without rupture from the Vater's papilla is determinant to resectability. So, it is of great importance to locate the papilla and keep it intact. We adopted preoperatively endoscopic marking and intraoperative
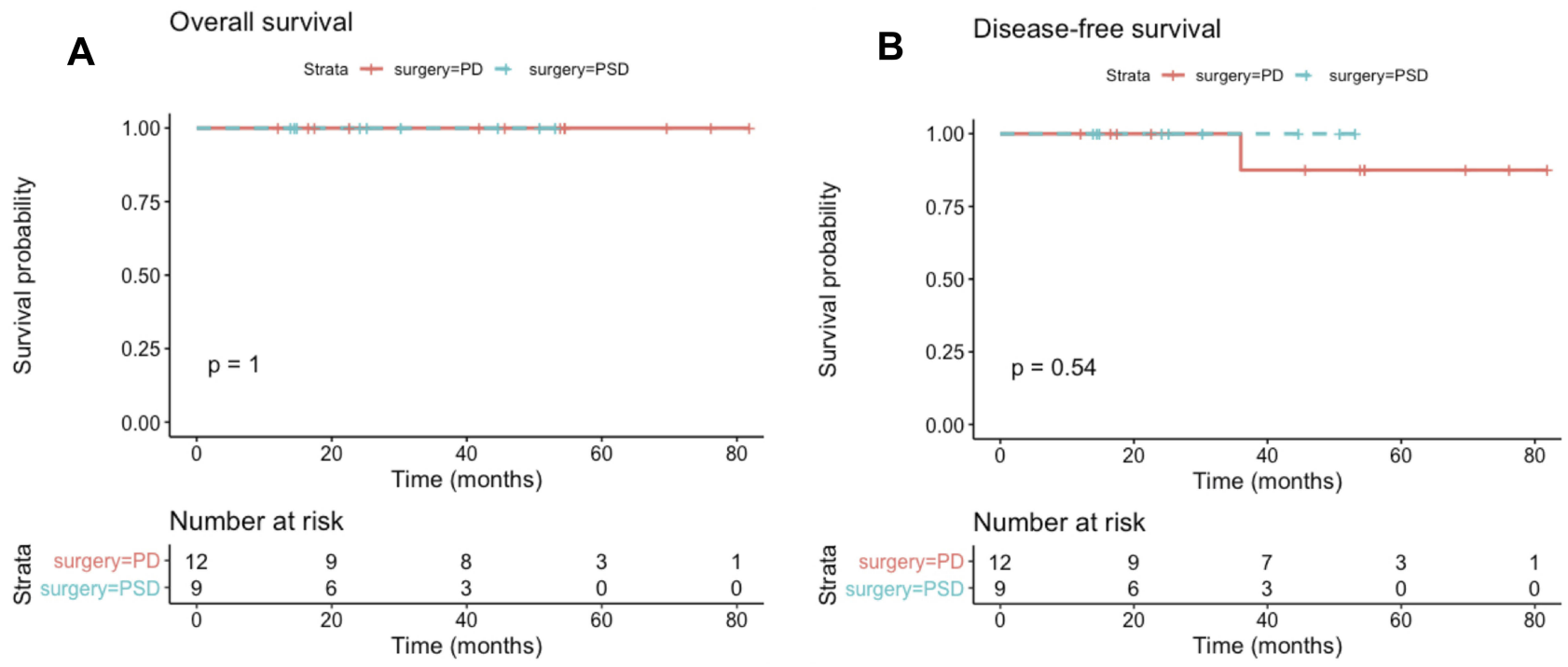

Figure 5 Overall survival (A) and disease-free survival (B) of patients underwent L-PD and L-PSD. 
cannulation of the catheter along the common bile duct with cholangiogram to ensure the ampulla. The catheter was placed to penetrate through the papilla and removed after the duodenojejunostomy. However, questions about PSD in curative surgery still exist. Lee et al reported that 84\% PSD group reached $\mathrm{R} 0$ resection and the remaining $16 \%$ required conversion to PD. ${ }^{21}$ While in this study, all the 9 patients intended to perform L-PSD were all succeeded without conversion to L-PD, and no ampulla injuries occurred. Only one patient complicated delayed gastric emptying (DGE), no stricture or fistula was observed. Similarly, Stauffer performed 10 PSDs and only experienced complication with 1 DGE because of pancreatic fistula, ${ }^{3}$ Chung reported 21 cases with only 2 pancreatic fistula and 1 wound infection. ${ }^{7}$ These show the technical feasibility and safety of L-PSD in selected hands.

L-PSD seemed to provide more attractive alternatives over L-PD for duodenal GISTs. However, to date, most studies focused on the feasibility while specific data on comparison between L-PSD and L-PD are still limited. Data on this issue are lacking, especially when taken laparoscopic management into consideration. Shen et al conducted a systematic review and concluded open PD group had significantly higher morbidities than that of the PSD group (40.8\% vs. $19.2 \%$, OR 2.90$).{ }^{2}$ Lee et al also indicated that the PD group had significantly greater intraoperative blood loss, longer operative time, longer hospital stay, and higher 90-day morbidity and readmission rates than that of the PSD group. This is also true in the set of laparoscopic surgery. In our study, the L-PSD group also confirmed much shorter operation time, less blood loss, faster recovery to off-bed, anus flatus and liquid intake. Moreover, L-PSD had much lower morbidity of both minor and major complications than that of L-PD, resulting in shorter length of hospital stay and less total cost. Obviating biliary-enteric and pancreatic-enteric anastomoses also free the L-PSD group out of long-term complications such as hepaticojejunostomy stricture and recurrent refluxing cholangitis, which affects the quality of life greatly. However, L-PD is irreplaceable for GISTs adjacent to the ampulla or large lesions that have a higher risk of rupture. Besides, L-PSD showed more acceptable clinical outcomes than L-PD for selected patients.

Another concerned question is whether L-PSD is an oncological adequate alternative to L-PD. Studies have shown that PD treatment was associated with worse longterm prognoses than PSD $(\mathrm{HR}=1.93,95 \%$ CI, 1.39-2.69; $P<0.001) .^{2}$ Moreover, Lee et al indicated that patients with descending GISTs who underwent PD had poorer DFS than PSD patients. However, in multivariate analysis, the PD group was revealed to have larger tumor sizes and the surgical procedure was proven to be irrelevant to the prognosis. $^{21}$ Similarly, our study showed that long-term DFS and OS had no significant difference between L-PSD and L-PD group, but this study failed to perform subgroup analysis for the limited sample size. Moreover, no lymph node metastasis was observed, and extra lymphadenectomy seemed unnecessary. L-PSD with negative margin had equivalent oncological outcomes when compared with L-PD.

However, the present study has several limitations. Firstly, the retrospective nature and small sample size may influence the validity of the analysis, but the incidence of duodenal GISTs is far low and the cases in a single center are limited. A multicenter study with prospective protocol is awaited to conclude more convincing results. Learning curve exists in both L-PD and L-PSD, and this may influence the outcomes. Moreover, the indication of adjuvant Imatinib and optimal duration has not been established, as Imatinib is very effective in most GISTs, it is difficult to evaluate the efficacy of the procedure without bias. Further analysis of prognostic factors including molecular characteristics is also important, which requires large-scale data.

\section{Conclusion}

L-PSD showed comparable safety and oncological benefits as L-PD, while having a much shorter operation time, less blood loss and much faster recovery. These resulted in much less total cost. For GIST located opposite to the major papilla, L-PSD should be applied in selected patients with experienced hands.

\section{Acknowledgments}

This study was supported by the Zhejiang Provincial Key Project of Research Foundations (Grant No.2015C03049) and the Natural Science Foundation of Zhejiang Province (Grant No. LGF20H1600011).

\section{Disclosure}

The authors have no conflicts of interest or financial ties to disclose.

\section{References}

1. Corless CL, Barnett CM, Heinrich MC. Gastrointestinal stromal tumours: origin and molecular oncology. Nat Rev Cancer. 2011;11:71. doi: $10.1038 / \mathrm{nrc} 3143$ 
2. Shen Z, Chen P, Du N, et al. Pancreaticoduodenectomy versus limited resection for duodenal gastrointestinal stromal tumors: a systematic review and meta-analysis. BMC Surg. 2019;19(1):121. doi:10.1186/ s12893-019-0587-4

3. Stauffer JA, Raimondo M, Woodward TA, et al. Laparoscopic Partial Sleeve Duodenectomy (PSD) for nonampullary duodenal neoplasms avoiding a whipple by separating the duodenum from the pancreatic head. Pancreas. 2013;42(3):461-466. doi:10.1097/MPA.0b013e31 82649956

4. Hoeppner J, Kulemann B, Marjanovic G, et al. Limited resection for duodenal gastrointestinal stromal tumors: surgical management and clinical outcome. World J Gastrointest Surg. 2013;5:16-21. doi:10. 4240/wjgs.v5.i2.16

5. Lee SJ, Song KB, Lee YJ, et al. Clinicopathologic characteristics and optimal surgical treatment of duodenal gastrointestinal stromal tumor. J Gastrointest Surg. 2019;23:270-279. doi:10.1007/s11605-018-3928-1

6. Goh BK, Chow PK, Kesavan S, et al. Outcome after surgical treatment of suspected gastrointestinal stromal tumors involving the duodenum: is limited resection appropriate? J Surg Oncol. 2008; 97:388-391. doi:10.1002/jso.20954

7. Chung JC, Kim HC, Hur SM. Limited resections for duodenal gastrointestinal stromal tumors and their oncologic outcomes. Surg Today. 2016;46:110-116. doi:10.1007/s00595-015-1163-x

8. Liao GQ, Chen T, Qi XL, et al. Laparoscopic management of gastric gastrointestinal stromal tumors: a retrospective 10-year single-center experience. World J Gastroenterol. 2017;23:3522-3529. doi:10.3748/ wjg.v23.i19.3522

9. Choi SH, Park J, Kang CM, et al. Laparoscopic partial sleeve duodenectomy for the infra-ampullary gastrointestinal stromal tumors of the duodenum. World J Surg. 2018;42(12):4005-4013. doi:10.1007/ s00268-018-4707-6

10. Chung JC, Chu CW, Cho GS, et al. Management and outcome of gastrointestinal stromal tumors of the duodenum. J Gastrointest Surg. 2010;14:880-883. doi:10.1007/s11605-010-1170-6

11. Corcione F, Pirozzi F, Sciuto A, et al. Laparoscopic pancreas-preserving subtotal duodenectomy for gastrointestinal stromal tumor. Minim Invasive Ther Allied Technol. 2013;22: 187-190. doi:10.3109/13645706.2012.698988
12. Joensuu H. Risk stratification of patients diagnosed with gastrointestinal stromal tumor. Hum Pathol. 2008;39:1411-1419. doi:10.1016/j. humpath.2008.06.025

13. Bassi C, Marchegiani G, Dervenis C, et al. The 2016 update of the International Study Group (ISGPS) definition and grading of postoperative pancreatic fistula: 11 years after. Surgery. 2017;1 61:584-591. doi:10.1016/j.surg.2016.11.014

14. Bassi C, Dervenis C, Butturini G, et al. Postoperative pancreatic fistula: an international study group (ISGPF) definition. Surgery. 2005;138:8-13. doi:10.1016/j.surg.2005.05.001

15. Clavien PA, Barkun J, de Oliveira ML, et al. The clavien-dindo classification of surgical complications: five-year experience. Ann Surg. 2009;250:187-196. doi:10.1097/SLA.0b013e3181b13ca2

16. Lu C, Jin WW, Mou YP, et al. Experience on postoperative complications of laparoscopic pancreaticoduodenectomy. Zhonghua Wai Ke Za Zhi. 2018;56(11):822.

17. Wang M, Peng B, Liu JH, et al. Practice patterns and perioperative outcomes of laparoscopic pancreaticoduodenectomy in China: a retrospective multicenter analysis of 1029 patients. Ann Surg. 2019; undefined:undefined.

18. Adam MA, Thomas S, Youngwirth L, et al. Defining a hospital volume threshold for minimally invasive pancreaticoduodenectomy in the United States. JAMA Surg. 2017;152:336-342. doi:10.1001/ jamasurg.2016.4753

19. Maher MM, Yeo CJ, Lillemoe KD, et al. Pancreas-sparing duodenectomy for infra-ampullary duodenal pathology. Am J Surg. 1996;171(1):62-67. doi:10.1016/S0002-9610(99)80075-0

20. Liu Z, Zheng G, Liu J, et al. Clinicopathological features, surgical strategy and prognosis of duodenal gastrointestinal stromal tumors: a series of 300 patients. BMC Cancer. 2018;18(1):563. doi:10.1186/ s12885-018-4485-4

21. Lee SY, Goh BK, Sadot E, et al. Surgical strategy and outcomes in duodenal gastrointestinal stromal tumor. Ann Surg Oncol. 2017;24:202-210. doi:10.1245/s10434-016-5565-9

\section{Publish your work in this journal}

Cancer Management and Research is an international, peer-reviewed open access journal focusing on cancer research and the optimal use of preventative and integrated treatment interventions to achieve improved outcomes, enhanced survival and quality of life for the cancer patient.
The manuscript management system is completely online and includes a very quick and fair peer-review system, which is all easy to use. Visit http://www.dovepress.com/testimonials.php to read real quotes from published authors. 